Dr. E. L. AsH gave the conclusions drawn from his personal experience in hypnotism. He considered that something more than verbal suggestion was wanted, which something might be the induction of hypnotic sleep or a combination of suggestion with material means of treatment. $\mathrm{He}$ believed that the latter was the more valuable conrse to adopt. It was, indeed, adopted in a half-hearted manner by every medical man who gave a placebo and told his patient that it would relieve his condition, but it should be done thoroughly and earnestly after a study of the individual indications in each case. Drugs, massage, and electricity were the adjuncts to treatment which he adopted particularly. Genuine hypnotism (the state of somnambulism) was unsatisfactory in practice. Only a small proportion of cases could be hypnotised, and these, in his experience, did no better than those treated by simple suggestion. He quoted two cases of nocturnal enuresis, one of which he had failed to cure by hypnotism whilst the other was cured by suggestion, and a case of blepharo-spasm which had been cured by suggestion with light massage on the eyelids, although a similar case treated only by suggestion had not been relieved. He submitted the following conclusions : (1) That suggestion should be much more commonly used as a routine method of treatment; (2) the advantages of aiding suggestion as a therapeutic measure by the induction of the hypnotic state seem to be very doubtful ; (3) that suggestion should be chiefly used as an adjunct to ordinary therapeutic methods, and regarded from this point of view is likely to ultimately prove to be one of the most valuable measures at our disposal; and (4) that the restriction of the practice of suggestive therapeutics to the narrow limits of a specialty, to the disregard of general medicine, is both unscientific and retrogressive.

Dr. W. H. BLAKE followed by describing a series of cases in which as a general practitioner he had used hypnotism with the utmost benefit. He insisted that it was impossible to ignore the value of mental therapeutic measures when such cases had been actually seen, and he urged the medical profession to master its principles. His most remarkable cures had been effected in a case of asthma for which the patient was accustomed to drench himself unavailingly with drugs, and in a severe case of dipsomania.

After some remarks by Mr. HAYDN BRowri,

Dr. Claye SHaw wound up the discussion by a few wise remarks, in the course of which he said that the Harveian Society was bound to admit the testimony which it had heard that hypnotism and suggestion were valuable agents in the cure of definite disease.

\section{BACTERIOLOGICAL INVESTIGATIONS ON SOME MODERN MOUTH DISINFECTANTS.}

\author{
By Dr. EuG. Prasecki. \\ (From the Hygienio Institute of the University of Lemberg, \\ Austrian Poland.)
}

THE city of Lemberg being alarmed by a severe epidemic of scarlet fever in the year 1908 the local sanitary authorities endeavoured to discover what preventive measures might be commonly adopted both in families and schools. Professor Dr. Raczynski drew the attention of the sanitary commission to formamint, the use of which had been strongly advocated by Dr. Meredith Young ${ }^{1 *}$ and others. It was accordingly resolved to submit this, and some other new drugs, to bacteriological investigation. Entrusted with this task by Professor Dr. Kucera (to whom I am greatly incebted for many kind suggestions), I decided to limit my inquiry to two newly-introduced methods-namely, antiseptic lozenges (formamint) and antiseptic spray (pyocyanase)

Although the nature of the great majority of infectious diseases which threaten the child of school age is not known, there is no doubt about the bulk of contagion being transmitted through the mouth or nose. This seems to be the case even with the acute exanthemata, where, amongst other proofs, we see inflammation of mucous membranes precede the cutaneous symptoms. A really effective method of disinfection of the mouth, nose, and pharynx must be, therefore, considered as a most powerful preventive against a whole series of maladies.

* The superior figures throughout the article refer to the bibliography at the end.
Amongst methods hitherto in use for this purpose I omitted / gargling, in the first place, because it does not affect the pharynx, at least as it is commonly used and as it can be taught to school children; and, in the second place, because very exact investigations of Röse ${ }^{2}$ have shown that really strong gargles irritate the mucosd too much to be used for hygienic or preventive purposes. Swabbing and douching are said to act very strongly, but, on the other hand, they require too much practice to be greatly employed outside hospitals. On the contrary, lozenges seem to be an ideal method from the purely technical point of view. Dr. Young has insisted on their merits so exhaustively that there is nothing to be added. The process of spraying, mentioned above, presents several well-marked advantages, two of which are that it requires no special training and covers very accurately the whole surface of both mouth and pharynx.

\section{A.-FORMAMINT.}

If we omit purely clinical observations, there has not been as yet much written on the subject. Rheinbold ${ }^{3}$ and Daus ${ }^{4}$ simply state that "formamint saliva" (i.e., saliva taken immediately after sucking of formamint tablets) develops a distinct bactericidal action; moreover, they do not care to give more exact quantitative calculations than those expressed by the terms "many" and "few" colonies. Jaenicke" published Loewenthal's observations, according to which five formamint tablets destroyed active movements in the case of bacillus fusiformis, spirillum sputigenum, and endamœba buccalis. Reissner was the first who endeavoured to estimate numerically the action of the drug. He gargled with tepid pump water and poured it afterwards into a sterilised glass vessel, from which a sample was taken on a loop of platinum wire and inoculated on agar plates. Colonies were counted after 24 hours' cultivation at the ordinary (!) temperature. This procedure was repeated at intervals of from two to ten minutes after sucking formamint tablets, the number of which was not stated. Three experiments of this kind showed reduction of the initial number of colonies to one-half after two minutes and to oneseventh after from five to seven minutes. Reissner also prepared several tables illustrating the action of formamint in vitro on different species of bacteria; as he does not, however, mention the method used, the description of this part of his work is incomplete. Meredith Young's article ${ }^{1}$ on the subject will be remembered by the readers of THE LANCET I shall therefore give only a brief summary of the results as far as they touch the bacteriological side of the question. Two experiments with formamint were made on a young healthy clerk whose bacterial flora amounted to 300,000 microbes on a swab with which the mucosa of the throat was touched on several consecutive "control" days. In the first of these the swab taken immediately after one tablet had been sucked was sterile; after ten minutes there were 35 microbes on the swab; and after 30 minutes there were 150 microbes on it. In the second experiment the man sucked two formamint lozenges-one every half-hour-and then gargled with sterilised water. The results were that the samples taken from the anterior faucial pillars showed 7500 colonies before the experiment and 80 colonies after it, while the samples from the posterior pharynx showed 965 colonies before the experiment and 80 colonies after it.

As to the details of the method, the swabs used were of constant size; they were brought into contact with the mucosa under possibly constant amount of pressure; each of them was immediately packed, labelled, and sent for examination to Professor S. Delépine who, after dilution of the initial sample in sterilised water, not only counted all colonies grown on agar plates at $37^{\circ} \mathrm{C}$., but also determined the number of colonies belonging to some particular species, including staphylococcus pyogenes aureus, staphylococcus pyogenes albus, streptococcus, and micrococcus tetragenus.

Proceeding to new investigations, the first question I endeavoured to answer was, To what extent, and in how strong concentration does formaldehyde (i.e., the disinfecting component of the drug) act in vitro as a disinfectant in human saliva? For this purpose I made a series of experiments from Oct. 3 rd to $15 \mathrm{th}, 1908$. I collected in a sterile glass from 6 to 8 cubic centimetres of my own saliva, and inoculated a sample of it in the manner described further on. Then I distributed the saliva in several tubes, 1 cubic centimetre in each, and added to each of them a different dose of formalin, except for one tube in which the saliva was left in the natural state. All the tubes were immediately 
placed in a thermostat at $37^{\circ} \mathrm{C}$, and samples therefrom were taken at certain intervals and inoculated. To prevent evaporation of the formaldehyde each tube was covered with a closely fitting glass cap. In two instances where I gave a formamint tablet instead of formalin, it was quickly pulverised in a sterile mortar and the tube was thoroughly shaken before taking each sample. Inoculation was executed by diluting 0.05 cubic centimetre of saliva in 5 cubic centimetres of physiological salt solution, and taking therefrom another 0.05 cubic centimetre for addition to ascites fluid, which mixed with an equal portion of agar liquefied at $45^{\circ} \mathrm{C}$., was poured out on plates and kept at $37^{\circ} \mathrm{C}$. for 24 hours.

In order to be able to compare the value of the disinfecting action in different experiments $I$ took the number of colonies in 1 cubic centimetre of saliva in the first proof (before adding formalin) as $=100$, and then calculated percentage numbers, showing the increase or diminution of the microbes, as had already been done by Röse. ${ }^{2}$ The results in " control" tubes (without formalin) were as follows :-

TABLE I.

\begin{tabular}{|c|c|c|c|c|c|c|c|c|c|c|}
\hline & & & & $\begin{array}{l}\text { th the } \\
\text { ginni }\end{array}$ & & $\begin{array}{l}10 \text { min. } \\
\text { later. }\end{array}$ & & $\begin{array}{l}30 \text { min. } \\
\text { later. }\end{array}$ & & $\begin{array}{l}60 \text { min. } \\
\text { later. }\end{array}$ \\
\hline Oct. & $5 \mathrm{th}$ & $\ldots$ & $\ldots$ & 100 & ...... & 198 & ....... & 106 & ...... & 132 \\
\hline ," & 7th & $\ldots$ & $\ldots$ & 100 & ...... & 93 & ...... & 152 & ....... & 167 \\
\hline , & 15 th & $\ldots$ & $\ldots$ & 100 & ....... & 61 & ....... & 93 & …...... & 51 \\
\hline
\end{tabular}

The absolute numbers at the beginning were respectively : $12,576,000,30,976,000$, and $35,360,000$ colonies from 1 cubic centimetre of saliva.

The figures from tubes to which different doses of formalin were added are ranged below according to decreasing quantity of the disinfectant :-

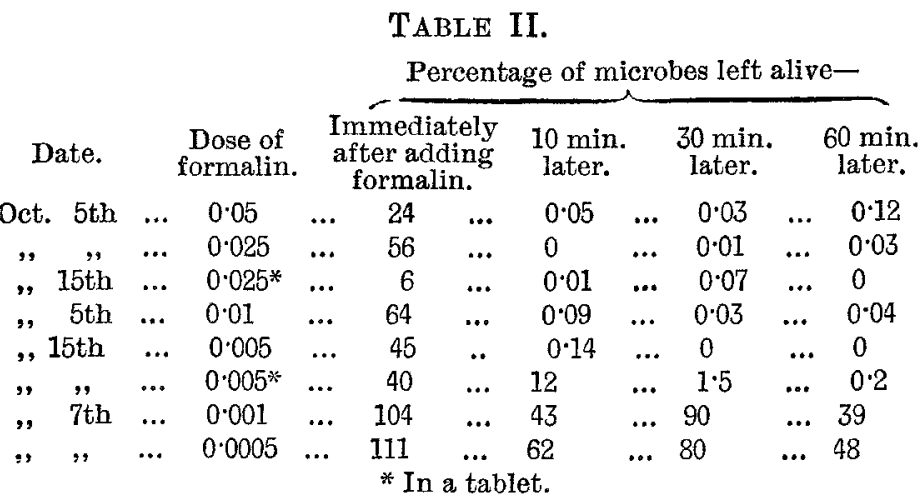

As repeated microscopical investigations showed that the character of the microbic flora in my saliva was fairly uniform, somewhat marked differences between the figures from Oct. 5th and, say, 15th are to be attributed chiefly to differences in the antiseptic action of the saliva itself (Clairmont ${ }^{7}$ ). Experiments with formamint tablets were made by adding one tablet ( $=0.025$ formalin) to 1 , or to 5 cubic centimetres of saliva, and they show an inferior antiseptic action as compared with corresponding quantities of pure formalin. The real volume of saliva in which a formamint tablet is dissolved during actual sucking in the mouth can be estimated to be 25 or 30 cubic centimetres. Accordingly, the first experiment on Oct. 7 th $(0.001$ formalin in 1 cubic centimetre of saliva) would be nearest the natural conditions ; but the figures-104, 43,90,39-ought to be somewhat increased (see above), and the antiseptic action, as estimated from experiments in vitro, would, therefore, not even equal an average of 40 per cent. in the first hour.

Repeated tests on the living subject, carried out on the same lines as in Dr. M. Young's experiments, gave contradictory results, which is easily understood, taking into account the rather weak action of the drug and the somewhat rough method. It is, for instance, impossible to ensure even an approximately constant amount of pressure of the swabs on the mucosa. I adopted, therefore, a more exact method-namely, that of Miller-Röse (Röse), ${ }^{3}$ which I modified in some details, With two healthy individuals ( $\mathrm{A}=$ the author, and $\mathrm{B}=\mathrm{a}$ school-boy 15 years of age), the bacteria contained in the saliva "normally" (i.e., without any drugs) were investigated, six or seven samples being taken at certain intervals during two or three hours. The whole daily curriculum of both individuals was carefully regulated, and especially during the test period of two or three hours all the appreciable conditions were kept equal. As taking meals and speaking aloud are known to reduce the amount of microbes in the cavity of the mouth each individual abstained from both eating and speaking during the whole period. With A the first sample was taken three-quarters of an hour after breakfast, and with $B$ one and a half hours after tea, both meals being carefully regulated as to both quality and quantity. This proof is to be found under C ("control") in each series. The second proof followed after 15 minutes, and as it corresponds in the "formamint" series to proofs taken immediately after suck ing the first tablet, it is designated as 0 . The following intervals are $-15,30$ minutes, 1 hour, 2 hours, and 3 hours after 0 .

Miller-Röse's method of taking proofs, which consists in gargling with an "indifferent" liquid (peptone, Witte, $1 \cdot 0$, chloride of sodium $5 \cdot 0$, and distilled water $1000 \cdot 0$ ), was, after two comparative experiments, found to be not more exact than a materially simpler way, which I therefore adopted. Proofs were taken by spitting about two cubic centimetres of saliva into a sterile tube, care being taken to avoid all forcible action of the respiratory or chewing muscles. From this I took 0.05 or 0.01 cubic centimetre of saliva and diluted it once or twice in physiological salt solution until the agar and ascites plate inoculated therewith contained from $\frac{1}{10} \sigma$ th to $\frac{1}{2} \frac{1}{\delta}$ th of the initial material. The plates were kept at $37^{\circ} \mathrm{C}$. for 24 hours, and the colonies were counted afterwards with the help of a microscope and a counting plate. This procedure limits, it is true, our investigation to the anterior portion of the cavity of the mouth, but, on the other hand, as in the "formamint series" the tablets were held just in the same portion during sucking, there is full evidence that our method detected the action of the drug in favourable conditions. The table below shows the results expressed (in the same way as above with experiments in vitro) in percentage figures:-

$$
\begin{aligned}
& \text { TABLE III. } \\
& \text { Person A. }
\end{aligned}
$$

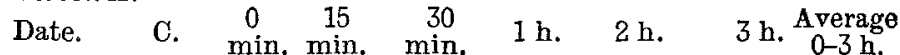

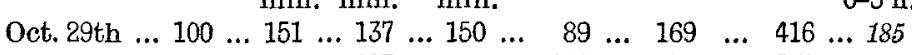

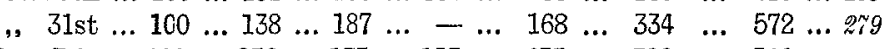

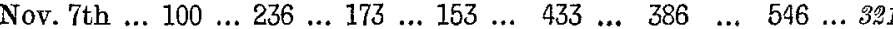

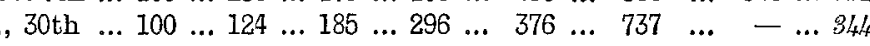

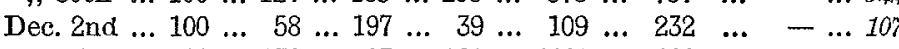

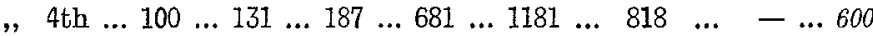

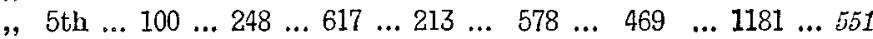

$$
\begin{aligned}
& \text { „, } 6 \text { th } \ldots \begin{array}{llllllllllll} 
& 100 & \ldots & 120 & \ldots & 319 & \ldots & 70 \ldots & 230 \ldots & -\ldots & -\ldots 185
\end{array}
\end{aligned}
$$

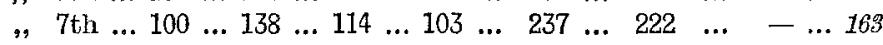

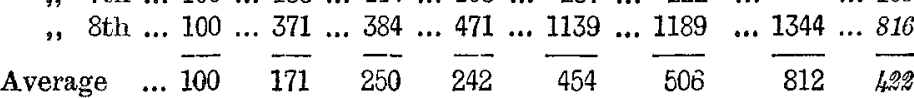

The absolute numbers of the colonies, calculated for 1 cubic centimetre of saliva, are in the column $O$ respectively: $6,336,000, \quad 8,832,000,6,000,000,5,715,000,5,900,000$, $1,600,000,2,300,000,6,000,000,12,200,000$, and $3,800,000$.

Person $B$

\section{TABLE IV.}

Date. C. $0 \mathrm{~min} .15 \mathrm{~min} .30 \mathrm{~min} .1 \mathrm{~h} .2 \mathrm{~h}$. Average $\begin{array}{lllllllllllllll}\text { Dec. 14th } & \ldots & 100 & \ldots & 120 & \ldots & 75 & \ldots & 77 & \ldots & 215 & \ldots & 74 & \ldots & 110\end{array}$ $\begin{array}{lllllllllllllllll} & \text { 21st } & \ldots & 100 & \ldots & 104 & \ldots & 190 & \ldots & 28 & \ldots & 20 & \ldots & 30 & & & 74\end{array}$ $\begin{array}{llllllllllllllll} & \text {, 31st } & \ldots & 100 & \ldots & 27 & \ldots & 123 & \ldots & 155 & \ldots & 200 & \ldots & 195 & \ldots & 140\end{array}$

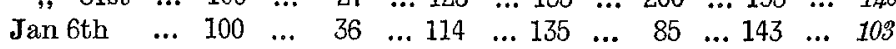
$\begin{array}{lllllllllllllllll} & 11 \text { th } & \ldots & 100 & \ldots & 45 & \ldots & 35 & \ldots & 47 & \ldots & 24 & \ldots & 60 & \ldots & 40\end{array}$

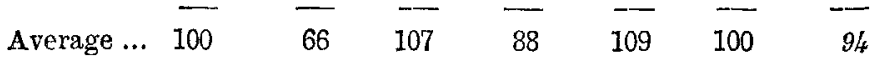

The absolute figures, relating to column $\mathrm{C}$, are : $92,800,000$, $49,200,000,27,500,000,17,500,000$, and $50,700,000$.

By these results Röse's conclusions are corroborated, according to which simple evaluation of bacteria-rate "before" and "after" taking a drug would not be suffciently exact for our purpose. With Person A, for instance, we see that the amount of microbes is rapidly growing during the observation period; any somewhat weak antiseptic action would, then, not be detected, the results showing us more microbes "after" in spite of the drug. Now, if we compare the above "normal" averages with corresponding averages from days in which the drug was taken, we shall detect the microbicidal action even where it simply consists in limiting the growth of bacteria-rate.

Now I proceeded to the formamint series. The first type 
of them (carried out with A only) consisted in experiments mucosa irritation, by which bactericidal action finally turns made in exactly the same way as above, with the unique into its reverse.

difference that during the whole interval between $\mathrm{C}$ (control) and 0 -proof two formamint tablets at once were sucked and swallowed. The results are to be seen in the table below :-

\section{TABLE V.}

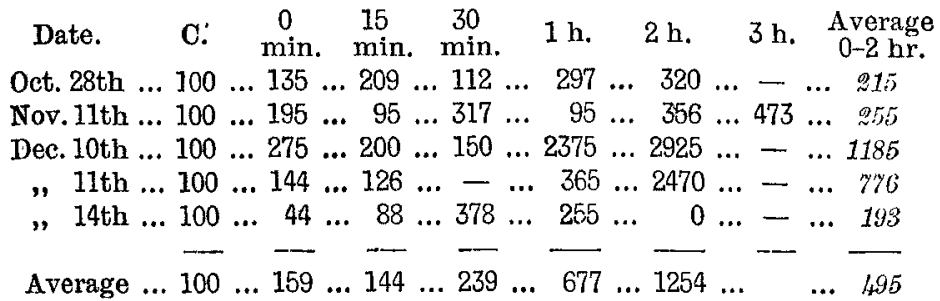

The absolute figures relating to column $\mathrm{C}$ are $4,672,000$, $5,375,000,400,000,5,700,000$, and 900,000 .

Compared with the average figures from the " normal" series, the above table shows the following differences, the mode of calculation being as follows. I took each of the average numbers of Table III. as $=100$, and calculated for such case the relative value of corresponding average figures in Table $V$. The differences $(-=$ bc low $100, t=$ above it) represent the amount of microbicidal action in the given moments of the observation period. For instance, Table III., column 0 , average 171 . If we take $i t=100$, the corresponding figure of Table V. (159) will amount to 93. Difference, -7 . Oonclusion: the drug developed, immediately after sucking, a microbicidal action of 7 per cent. - i.e., killed 7 per cent. of the bacteria. $\mathrm{C}, \pm 0 ; 0$ minute, $-7 ; 15$ minutes, $-42 ; 30$ minutes, $-1 ; \overline{1}$ hour, $+49 ; 2$ hours, +147 ; average (from 0 to 2 hours), +52 . After a short period of antiseptic action, there is, then, an absolute disappearance of this action about half an hour after swallowing, followed by increased growth of bacteria, which amounts, after two hours, to nearly $\mathbf{1 5 0}$ per cent. of the normal rate. This somewhat paradoxical result can be understood when compared with similar phenomena observed by Röse ${ }^{2}$ after gargling with some liquid mouth disinfectants. This author demonstrated that some strong disinfectants lower the vitality of the epithelium of the mucous membrane, and thereby produce, after a short period of a decreased rate of bacterial growth, conditions more favourable to bacterial growth than before. I felt, therefore, authorised to consider the dose of two tablets (at least for A) as too large a one, and gave, in the subsequent series, smaller doses (one tablet each), repeated at intervals of half an hour. Tablets were held in the mouth as long as possible (by $\mathrm{A}$ for 15 minutes and by $\mathrm{B}$ for from 5 to 8 minutes), the second inoculation was made, as above, immediately after the first dose, consecutive inoculations, on the contrary, inasmuch as they coincided with taking of tablets (i.e., at 30 minutes, 1 hour, and 2 hours) before the latter, so that instantaneous effects of formamint are registered in the column 0 only. A took during three hours six tablets, and B took during two hours four tablets. The results with $\mathrm{A}$ (calculated as above) are shown below :-

TABLE VI.

Date. $\quad$ C. 0 min. $15 \mathrm{~min} .30 \mathrm{~min} .1 \mathrm{~h}, \quad 2 \mathrm{~h} .3 \mathrm{~h} . \quad \begin{gathered}\text { Average } \\ 1-3 \mathrm{~h}\end{gathered}$ $\begin{array}{lllllllllllllllllll}\text { Nov. } 8 \text { th } & \ldots & 100 & \ldots & 50 & \ldots & 97 & \ldots & 67 & \ldots & 318 & \ldots & 226 & \ldots & 195 & \ldots & 159\end{array}$

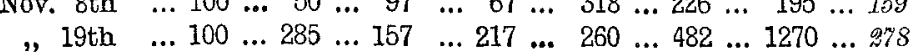
$\begin{array}{lllllllllllllllll}\text { Dec. } 9 \text { th } & \ldots & 100 & \ldots & 91 & \ldots & 139 & \ldots & 139 & \ldots & 191 & \ldots & 117 & \ldots & 717 & \ldots & 232\end{array}$

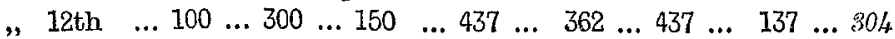
$\begin{array}{lllllllllllllllllll} & 13 \text { th } & \ldots & 100 & \ldots & 191 & \ldots & 83 & \ldots & 375 & \ldots & 25 & \ldots & 150 & \ldots & 341 & \ldots & 194\end{array}$

$\begin{array}{llllllllllllllllllll}\text { Average } & \ldots & \overline{100} & \ldots & \overline{183} & \ldots & \overline{125} & \ldots & \overline{167} & \ldots & \overline{231} & \ldots & \overline{282} & \ldots & \overline{692} & \ldots & .979\end{array}$

The absolute figures relating to column $\mathrm{C}$ are : $9,600,000$, $1,600,000,2,300,000,800,000$, and 1,200,000.

The differences from the "normal" series (calculated as above) are: $\mathrm{C},+0 ; 0$ minute, $+6 ; 15$ minutes, -50 30 minutes, -31 ; 1 hour, -49 ; 2 hours, $-44 ; 3$ hours, - 15; average $(0-3$ hours -34 -i.e., bactericidal action does not, on the average, rise higher than 34 per cent., whereas its maxima amount to 50 per cent. If we consider that there were, on the average, at the end of the observation period, about $13,000,000$ bacteria in 1 cubic centimetre of saliva still alive, such a degree of disinfection can hardly be of any practical value. Besides, we see at the end of some series (Nov. 19th, Dec. 9th) considerable growth of microbes, from which it seems to follow that even with small, repeated doses of the drug there can be

Person $B$

Date.

Jan. 3rd

, 8th

Average ... 100

The absolute figures relating to column $\mathbf{C}$ are $39,200,000$ $35,000,000$, and $12,700,000$.

The differences from the average " normal" figures (calculated as above) are: $\mathrm{C}, \pm 0 ; 0$ minute, $+61 ; 15$ minutes, - 14; 30 minutes, + 5; 1 hour, $-23 ; 2$ hours, - 49 ; avcrage, $-\mathcal{O}:$ an inconstant, and, on the average, very weak action.

The reason of the difference shown by $B$, as compared with $A$, seems to consist, at least partially, in the fact mentioned above, that $B$ was unable to hold the tablets in his mouth, as a rule, even half as long as $\mathbf{A}$, whereby naturally the duration of the drug's action on the contents of the mouth was considerably limited. This was the case, though I never omitted reminding $B$ of the necessity of tablets being held as long as possible. There is every probability that with younger children the duration of tablet sucking would be still shorter in accordance with the smaller degree of will power and the smaller degree of ability to concentrate the attention. It follows, then, that just within those age limits where formamint should do the greatest services we are entitled to anticipate still weaker effects.

Rosenberg ${ }^{\circ}$ proved, it is true, the presence of formaldehyde in the blood after a formamint tablet had been sucked; thus one lozenge might act even after being completely swallowed. If, however, the concentration of aldehyde in the blood were sufficient to be taken into account, its action would be detected in the later stages of our observation period.

To the above conclusions an objection might still be made - namely, that bacteria which were left alive might belong to some more resistant species. This I partially prevented by using ascites-agar. We know that on ascites-agar a series of more delicate species (micrococcus meningitidis gonococcus, pneumococcus, \&c.) find better conditions of growth, whereas ordinary, more resistant saprophytes grow thereon worse than on pure agar. Besides, I proceeded to definition of species. Unfortunately, we do not possess as yet methods suited to define the species of each colony on fairly densely inoculated plates. I could, therefore, do no more than (1) direct my attention when counting the colonies constantly to their morphological characters; and (2) examine microscopically a series of proofs belonging to colonies which seemed to represent different species. With Person A I found in the series with six tablets from Nov. 8th in all the plates an overwhelming majority of streptococcus pyogenes. There were also a few colonies of bacilli belonging to the subtilis group and a species of Gram-positive micrococcus. In a series of the same kind from Nov. 19th on all plates only streptococcus was found, except one (0 minute), in which, on four colonies investigated, two belonged to pneumococcus. With Person $B$ in the series from Jan. 8th (four tablets) in all plates almost exclusively micrococcus catarrhalis was found. Of other species we saw a few pneumococci, streptococcus pyogenes, and very small numbers of saprophytes (namely, Grampositive large micrococci, and very rarely bacilli belonging to the subtilis group). As far as can be seen from the aspect of colonies, the bacterial flora of the other series must have been of much the same composition. There is, consequently, no reason to believe that the bactericidal factor had any particular difficulties to beat, as colonies of more resistant species (spore-producing bacilli) formed everywhere a vanishing minority, and were often totally absent. Neither was there any evidence of the so-called "selective" action (by which certain species are killed or have their growth limited and others are spared); the flora of the last plates in a series had the same character as that of the first or "control" plate. As to Person B, the aspect of the immense majority of the colonies (especially the superficial ones) cultivated from his saliva was that of micrococcus catarrhalis, alike in the times of perfect health and during slight catarrh of the nose. It is conformable with the observations of Arkwright, ${ }^{9}$ who did not find micrococcus catarrhalis more frequently in 
the noses of persons suffering from catarrh than in normal noses.

Conolusions.-1. Formaldehyde develops in vitro, in certain concentrations, a strong bactericidal action on the flora of the saliva of healthy individuals. In concentrations, however, which can be considered as nearest to natural conditions with formamint tablet sucking, its action is weak. 2. Investigations carried out in the living subject give similar results. In the first place, after a large single dose of formamint (two tablets) there is a transitory bactericidal action, followed by a considerably augmented growth of bacteria in the cavity of the mouth. In the second place, with smaller, frequently repeated, doses (single tablets at one and a half hours' interval) the growth of bacteria is no doubt lessened, but only to an extent to which hardly any practical value can be attributed.

\section{B.-PyOCYANASE}

Emmerich and Loew ${ }^{10}$ saw that in mixed bouillon cultures which contained mostly bacillus pyocyaneus, the sediment as well as the superficial film (both composed of bacteria) disappeared after long standing. They attributed this to bactericidal ferments, acting not only upon the species which produced them. Further investigations corroborated this supposition. Old bouillon cultures of bacillus pyocyaneus, separated from bacteria and their residues and brought by evaporation to one-tenth of their initial volume, gave a liquid containing several proteolytic enzymes (nucleases); these observers named it pyocyanase. According to quite recent investigations (Schapiro ${ }^{11}$ ) a number of bacterial species can be divided into three groups in accordance with their susceptibility to the action of pyocyanase. The liquid acts strongly on bacillus diphtheriæ, bacillus pseudodiphtheriæ, xerosis, vibrio choleræ, streptococcus pyogenes, pneumococcus, gonococcus, meningococcus, bacillus fæcalis alkaligenus, and bacillus dysenteriæ (Shiga). An intermediate position is occupied by bacillus typhi, bacillus paratyphi A, staphylococcus pyogenes aureus, micrococcus tetragenus, and bacillus pneumoniæ (Friedländer). A weak action is developed against bacillus coli, bacillus paratyphi $B$, and bacillus enteritidis; whereas bacillus pyocyaneus, bacillus fluorescens, and proteus find even conditions of growth in pyocyanase.

From these observations great advantages might be expected for the problem of so-called internal disinfection. The means which hitherto have been used for this purpose in addition to their bactericidal effects, produced more or less pronounced injurious effects on the tissues of the human body, whereas the bacteriolytic enzymes, being free from this defect, may be applied without fear in proper concentration to the mucous membranes.

Clinical and bacteriological investigations on spraying with pyocyanase in diphtheria (Zucker, ${ }^{12}$ Muehsam ${ }^{13}$ ) encourage the use of it together with antidiphtheritic serum. In an epidemic of grippe caused by micrococcus catarrhalis, and observed in infants at a clinique in Vienna, Escherich and Jehle ${ }^{14}$ proved that from 24 to 48 hours after pyocyanase had been instilled into the nose there was a total absence of micrococcus catarrhalis. Jehle ${ }^{14}$ administered pyocyanase by instillation in the course of an epidemic of cerebro-spinal meningitis to a series of patients as well as to healthy "contacts" in whose naso-pharyngeal cavity meningococci were found. The meningococci disappeared after one or two applications of pyocyanase.

It is obvious, then, that in several diseases in which the mouth and the nasal cavity are unquestionably the only door of infection we may expect favourable results from pyocyanase as experience has shown. I do not refer here to the technical details of the investigations mentioned above, because they seem to be quite irreproachable, and in this respect they form a contrast to much that has been written about formamint. The question I proposed to myself was, Can the growth of bacteria in the cavity of the mouth in healthy persons be limited by the application of pyocyanase in a degree suited for general hygienic and preventive purposes?

The choice of method did not cause any difficulties. In order that they might admit of comparison with the previous investigations of the action of formamint observations were made on the same person $A$, and, as a basis for the appreciation of bactericidal action, the same series of "control" experiments was used, the results of which are shown above in Table III. In the usual course of experiments the following changes ensued, as compared with the "formamint series." Immediately before the second inoculation (marked on the table with 0), I made, exactly in the manner described by the inventors, 20 sprayings with pyocyanase in two series of ten sprayings each, with an interval of five minutes between them, the utmost care being taken to cover equally the whole cavity of the mouth. Each compression of the bag was as complete as possible. The excess of pyocyanase left in the mouth was spat out. A curious phenomenon connected with these cases was intense salivation, which lasted over an hour or so. The colour of the two or three first samples of the saliva (i.e., until 30 minutes after spraying) was greenish. The results (calculated as above) are ranged below.

\section{TABLE VIII.}

Date. C. 0 min. $15 \mathrm{~min} .30 \mathrm{~min} .1 \mathrm{~h}$.

$$
\text { 2h. } 3 \text { h. Average }
$$

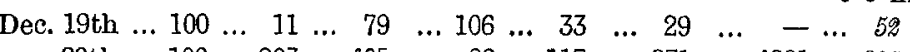

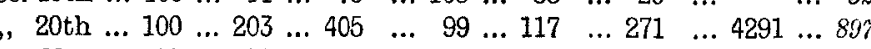

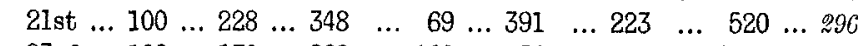

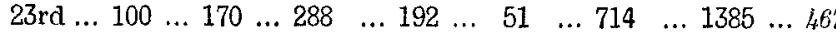

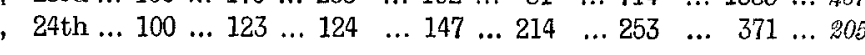$$
\begin{array}{llllllll}
\text { Average ... } 100 & 147 & 249 & 123 & 161 & 298 & 1642 & 388
\end{array}
$$

The absolute figures relating to column $\mathrm{C}$ are $: 7,500,000$ $1,650,000,1,100,000,2,700,000$, and $5,925,000$.

The differences (calculated as with formamint) from the "normal" series shown in Table III. are as follows: $\mathrm{C}, \pm 0 ; 0$ minute, $-14 ; 15$ minutes, -1 ; 30 minutes, - $49 ; 1$ hour, - 65; 2 hours, - 41; 3 hours, +101 ; average ( 0 to 3 hours $),-9$. In spite of considerable oscillations, the bactericidal action of the liquid was therefore from 30 minutes to 2 hours after the application, a fairly distinct one ; in some series, however (Dec. 20th and 23rd), the decrease of the bacteria rate turns during the third hour into its reverse; we have again an "irritation," just as in the series with a large single dose of formamint (see above).

These results lead me to suppose that, for Person A at least, we shall be perhaps nearer the optimum of pyocyanase action when giving, during the observation period of three hours, two smaller doses. In five ensuing experiments I accordingly made immediately before the second inoculation ten sprayings only, whereas ten other sprayings were executed at the middle of the observation period-i.e., one and a half hours after the second inoculation (between the fifth and sixth inoculations). The results are shown below :-

\section{TABLE IX}

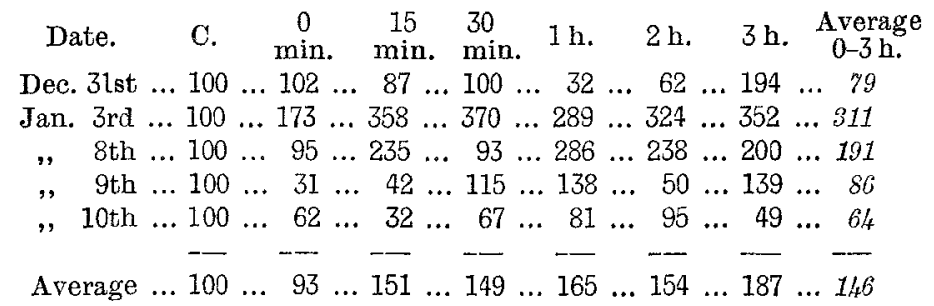

The absolute figures relating to column $\mathrm{O}$ are : $15,525,000,7,900,000,6,200,000,12,050,000$, and $13,975,000$. Calculated as with formamint, the differences from the normal series are: $\mathrm{C} \pm 0 ; 0$ minute, $-46 ; 15$ minutes, $-40 ; 30$ minutes, $-\overline{39} ; 1$ hour, $-66 ; 2$ hours, -70 ; 3 hours, - 77 ; average (0 to 3 hours), - 66. The rate of the growth of bacteria in the cavity of the mouth was accordingly less by from 39 to 77 per cent. (on the average by 66 per cent.), as compared with observations during which no drug was applied. Contrary to Table VIII., the action shows here a fairly constant increase towards the end of the observation period. Moreover, if we compare the figures obtained, not to speak about formamint, with those given by other mouth disinfectants which were recommended after investigation by sufficiently exact methods. (e.g., mouth washes, Röse ${ }^{2}$ ), we must consider pyocyanase, when used in the way described, as the strongest of them.

As to definition of species, microscopical investigations were made on plates from Dec. 24th, 31st, and Jan. 3rd, in the first of these series the bulk of the bacteria being streptococci; about a quarter of the colonies on all the plates belonged to micrococcus catarrhalis. On the two other days 
(Person A had then a slight pharyngitis) an immense majority of micrococcus catarrhalis was found; of other species there was only pneumococcus. A "selective" action of pyocyanase (stronger on some than on other species) was not detected.

We had, then, just as in the preceding observations, a bacterial flora of fairly uniform composition. belonging to species which resist disinfectarts less strongly. Schapiro ${ }^{11}$ assigns streptococci and pneumococci to the least resistant group as regards pyocyanase; he does not, however, mention micrococcus catarrhalis, about which we conclude from Jehle's dissertation ${ }^{14}$ that it is easily killed by pyocyanase. I endeavoured, therefore, to calculate the bactericidal power of pyocyanase in relation to that microbe, and for that purpose used Schapiro's method. To an ascites-agar culture of micrococcus catarrhalis (cultivated from the mouth of Person A) I added 2 cubic centimetres of bouillon and made an emulsion of bacteria with the help of a loop of platinum wire. From this I transferred, with a pipette, 0.2 cubic centimetre to a tube containing 2 cubic centimetres of pyocyanase, and placed the latter, together with a "control" tube ( 2 cubic centimetres of pure bacteria emulsion), in a thermostat at $37^{\circ} \mathrm{C}$. I then inoculated samples from both tubes at certain intervals. As to inoculations, $0 \cdot 1$ cubic centimetre of well-shaken liquid was diluted in 5 cubic centimetres of physiological salt solution, and from this mixture the same quantity was again diluted in the same manner. From this second dilution 0.1 cubic centimetre was trans. ferred to ascites fluid which was, together with agar liquefied at $45^{\circ} \mathrm{C}$., poured out on plates. The results (counted after 24 hours' cultivation at $37^{\circ} \mathrm{C}$. and calculated for 1 cubic centimetre of liquid) are given below :-

\section{TABIE X.}

$15 \mathrm{~min} .40 \mathrm{~min} . \quad$ ' $1 \mathrm{~h} . \quad 24 \mathrm{hr}$.

Bouillon emulsion $\ldots \quad 4,925,000 \ldots 7,700,000 \ldots 7,225,000 \ldots$ Impossible

$10 \%$ of emulsion in pyocyanase

$$
\begin{array}{lll}
200,000 & \cdots & 275,000 \\
(=4 \%) & \cdots & 175,000 \\
(=3 \%) & (=2 \%)
\end{array}
$$

The stock now investigated proved a little more resistant than the species ranged by Schapiro in his first group. On the other hand, it is to be considered far more sensitive to the action of pyocyanase than Schapiro's second group. This fact, together with the results of our experiments in the living subject in which micrococcus catarrhalis was not destroyed by pyocyanase in the course of tbree hours, lead us to conclude that, in spite of the results obtained by Escherich and Jehle with infants, we cannot expect a similar marked action of pyocyanase upon micrococcus catarrhalis in adults.

Conclusions.-1. Pyocyanase sprayed into the cavity of the mouth in a large single dose may sometimes, after a transitory period of bactericidal action, cause increased growth of microbes. 2. When sprayed in smaller, repeated doses pyocyanase develops a higher bactericidal action than any other mouth disinfectant which has hitherto been recommended after exact investigation. Before we can recommend pyocyanase, however, for daily use by healthy persons more extensive investigations are indispensable. Such a recommendation must be withheld until the perfect innocuity of the liquid for the mucous membrane of the human mouth is proved. Circumstances have unfortunately prevented me from carrying out such investigations.

Bibliography.-1. Meredith Young: Modern Methods of Treating Infective Conditions of the Throat, THE LANCET, March 28th, 1908 p. 924. 2. C. Rỏse: Untersuchungen über Mundhygiene, Zeitschrift fiür Hygiene, 1901, vol. xxxvi., p. 161. 3. Rheinboldt; Ueher den Desinfektionswert des Formamints, Deutsche Medizinische Wochenschrift, 1906, No 15.4 . S. Daus: Zur Desinfizierenden Wirkung des Formaldehyds anf Schleimhäute, Medicinische Klinik, 1906, No. 16 5. P. Jaenicke: Zur Desinfizierenden Wirkung des Formaldehyds ac Schleimhäute, ibiđ., No 30 . 6. A. Reissner : Bin Beitrag zur Übun der Mundhygiene bei Kindern. Deutsche Zahnaerztliche Zeitung, 1907 No. 142. 7. P. Clairmont : Ueber das Verhalten des Speichels gege die Bakterien, Wiener Klinische Wochenschrift, 1906, vol, xix , p. 1397. 8. Rosenherg: Therapie der Gegenwart, 1905, Heft 2. 4. 9. Arkwright On the Occurrence of the Micrococcus Catarrhalis in Normal an Catarrhal Noses, \&c., Journal of Hygiene, 1908, vol. vii., p. 145. 10. Emmerich and Loew: Bakteriolytische Finzyme als Ursache der erworbenen Immunität, \&c., Zeitschrift für Hygiene, vol. xxxi. 11. L. Schapiro: Veber das baktericide Verhalten der Pvocyanase, \& $c$ Hygienische Rundschau, vol. xvili., 1908, p. 453. 12. Zucker: Zur Tokalen Behandlung der Diphtherie mit Pyocyanase, Archiv für Kinderheilkunde, vol xliv, 13. Muehsam. Ueber Pyocvanasebehandlung der Diphtherie Deutsche Medizinische Wochenschrift, 1908, 231 , 14 Jehle. Beobart Kinderhilkm 1906 , 716, 15 Ueber das Vork, kme., Jahrbuch ner coccus, \&c., Wiener Klinische Wochenschrift, 1907, No. 1.

\section{THE PROPOSED FORMATION OF A SPECIAL CIVIL MEDICAL SERVICE IN INDIA.}

AT a meeting of the members of "the independent medical profession" of the Bombay Presidency held on Sept. 8th at Bombay under the auspices of the Bombay Medical Union and the presidency of Sir Bhalchandra Krishna, L.M., a memorial unanimously adopted was directed to be forwarded through the proper authorities to the Secretary of State for India (Lord Morley), dealing with the question of the present position of the independent practitioners of India and their claims that all civil medical appointments at present controlled by the Government of India should be thrown open to native practitioners, and that what they consider the present monopoly of these posts by officers of the Indian Medical Service should be done away with. The memorial, which is a lengthy one, has evidently been evoked by Lord Morley's recent despatches to the Viceroy of India, in which the former foreshadowed that no further increase in the personnel of the civil side of the Indian Medical Service would be approved, and that a strong effort should be made by the authorities in India to employ medical practitioners locally to fill appointments where suitable candidates were forthcoming. There can be no doubt that Lord Morley's pronouncement evoked feelings of keen satisfaction amongst native Indian practitioners, and their feelings are now echoed in the memorial which they have drawn up. The request for recognition, coming as it does from the educated Indians of Bombay Presidency, will obtain the sympathetic consideration of the India Office. Nevertheless, we regret to note that the memorialists have thought fit to embody what can only be considered as an indictment of the pioneer medical service of India-the Indian Medical Service-and this is not only unjust but tactless, as over 90 per cent. of the native practitioners who now demand to share in the medical appointments in India owe their very existence, their teaching, and their licences to practise in India, to the very service they now arraign.

By the medical profession of the United Kingdom little is known or understood of the ways and means whereby the medical administration of India is carried out. Medical education of the native practitioners is carried out by the medical colleges. These institutions are financed and controlled by the State, and in the majority of instances education is free. The appointments to professorships and lectureships in these colleges are made by the Government after due consideration of the names of suitable candidates put forward by the Director-General of the Indian Medical Service. Likewise appointments to civil surgeoncies are made, and sanitary and public health appointments are made on nominations put forward by the Sanitary Commissioner to the Government of India, who is also an officer of the Indian Medical Service. On the other hand, appointments on the military side are made by the Commander-in-Chief from nominations put forward by the Principal Medical Officer of His Majesty's Forces in India. Members of the independent practitioner class have no representative to foster their interests on the headquarter staff of either the civil or military supreme government. But as a matter of fact, neither the civil nor military medical service has any medical representative on the Viceroy's Council, and medical and sanitary questions have no prominent position, as they are included amongst a shoal of other matters in the "portfolios" of the "Home" and "Army" members. Sanitation and allied sciences suffer accordingly. These facts are stated in the memorial from Bombay, which brings home the inadequate representation of the profession generally in the government of a country where matters of health should occupy a very much more important position than they are allowed to do at present.

The memorialists suggest certain lines along which their proposed scheme of reform might be directed. The more important of these point out that all appointments in the civil medical profession should be thrown open to proved merit and ability wherever found, and that the sons of the soil, meaning the native practitioners, should have an equal chance with the Indian Medical Service to compete for such appoint. ments, their fitness being based on merit, qualifications, and other credentials alone, and not on any class membership or consideration of supposed service exigencies. They recommend 